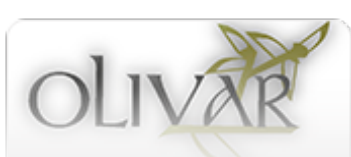

Olivar

ISSN: $1852-4478$

publicaciones@fahce.unlp.edu.ar

Universidad Nacional de La Plata

Argentina

\title{
Cualquier tiempo pasado fue peor. Reflexiones sobre la narrativa vasca post-ETA'
}

\author{
Olaziregi, Mari Jose \\ Cualquier tiempo pasado fue peor. Reflexiones sobre la narrativa vasca post-ETA ${ }^{1}$ \\ Olivar, vol. 19, núm. 30, 2019 \\ Universidad Nacional de La Plata, Argentina \\ DOI: https://doi.org/10.24215/18524478e060
}

Esta obra está bajo una Licencia Creative Commons Atribución-NoComercial-Compartirlgual 4.0 Internacional 


\title{
Cualquier tiempo pasado fue peor. Reflexiones sobre la narrativa vasca post-ETA ${ }^{1}$
}

Old times were worse. Reflections on post-ETA Basque narrative

Mari Jose Olaziregi

DOI: https://doi.org/10.24215/18524478e 060

Universidad del Pais Vasco-Euskal Herriko Unibertsitatea,

España

\section{Resumen:}

En las líneas que siguen, trataremos de reflexionar en torno a las consecuencias que el cese de la actividad armada de ETA ha tenido en el panorama de la novela en lengua vasca. Para ello, y antes de abordar la lectura y análisis de algunas obras representativas, realizaremos una introducción en torno a las peculiaridades que ha tenido la representación del conflicto vasco en la narrativa vasca, así como su evolución temática y formal. Terminaremos nuestro análisis con la lectura de las propuestas novelescas de los escritores vascos Ramon Saizarbitoria, Harkaitz Cano, Katixa Agirre, Lander Garro y Uxue Alberdi. Aspectos como el de las víctimas primarias y secundarias, la herencia recibida y su transmisión, o la transformación de una identidad nacional resistente, guiarán nuestro análisis.

Palabras ClaVE: Literatura vasca y ETA, Narrativa vasca actual, Memoria histórica.

\begin{abstract}
:
In what follows, we will try to reflect on the consequences that the end of ETA's armed activity has had in Basque-language novels. In order to do so, and before addressing the interpretation and analysis of some representative works, we will present an introduction about the particularities of representation of the Basque conflict in Basque narrative as well as its thematic and formal evolution. We will end our analysis with an interpretation of some novels by the Basque writers Ramon Saizarbitoria, Harkaitz Cano, Katixa Agirre, Lander Garro, and Uxue Alberdi. Our analysis will be guided by aspects such as that of primary and secondary victims, the inheritance received and its transmission, and the transformation of a resistance national identity.
\end{abstract}

KEYWORDS: Basque literature and ETA, Contemporary Basque narrative, Historical memory.

Corría diciembre del año 2010 y los integrantes de la revista Volgako Batelariak [Bateleros del Volga] (2005-2013) repartían pasquines durante la Feria del Libro y Disco de Durango, la más importante en la producción editorial y musical vasca. En su tradicional tono humorístico, los integrantes de la revista reflexionaban sobre los retos que la literatura en lengua vasca debería afrontar tras la desaparición de ETA ${ }^{2}$. Como era de esperar, una de las principales cuestiones la constituía, sin duda, la pregunta sobre la incidencia que la desaparición de la banda armada pudiera tener en la hasta entonces abundante literatura sobre el conflicto vasco. ¿Cómo sería la literatura post-ETA ¿ ¿ Ocurriría lo mismo que había ocurrido con el tema de la Guerra Civil en la literatura española, y se convertiría en un tema del pasado, cuasi fosilizado? O al contrario, como afirmara el escritor Stuart Neville a propósito de la literatura irlandesa, ¿estaba la mejor literatura vasca sobre el tema por venir?

ETA había declarado el alto el fuego el 5 de septiembre de 2010, pero no fue hasta el 30 de octubre de 2011 cuando anunció el cese definitivo de la actividad armada, así como su posterior disolución, el 3 de mayo de 2018. Hablamos de una cronología, trágicamente marcada por un itinerario de violencia iniciado en 1959 , que tuvo sus picos, o años más sangrientos, durante los años 1980. Una violencia que, como no podía ser de otro modo, ha sido representada en la creación cultural vasca de las últimas décadas y que, en el caso concreto de la literatura, ha constituido, además, como recordaban los Bateleros del Volga, un núcleo de tensión y constante debate en la comunidad literaria euskaldun (vascoparlante). 
De hecho, tal y como recogíamos en publicaciones anteriores (Olaziregi, 2017, p. 7) los escritores vascos han aludido reiteradamente al papel performativo y destabuizador de la literatura en la representación de conflictos armados y sus consecuencias. Incluso, por citar a un autor integrante del grupo con el que iniciábamos esta reflexión, Iban Zaldua (2016, p. 1153), se ha aludido al poder homeopático que pudiera tener la obra literaria. Pero reflexionar sobre el deber de la literatura y su alcance para contribuir a aliviar el dolor o a dibujar una vía reflexiva que contribuya a la resolución y restitución del daño causado, no es en absoluto fácil. Máxime, cuando hablamos de un contexto, el vasco, en el que la socialización del debate sobre décadas de terrorismo pasa por una clara politización de los medios de comunicación. De hecho, incluso el propio término de conflicto vasco ha sido origen de debate. En este sentido, tendríamos que matizar que en el contexto vasco, el término "conflicto vasco" correspondería, entre otras acepciones, al relato que la izquierda abertzale fue gestando desde el período inicial de la banda (años 1958-1968). Como explica la historiadora Leyre Arrieta (2015, p. 23), fueron años en los que se estableció la estrategia armada, años en los que se demarcaron las primeras víctimas y se fue gestando una narrativa, alentada también por publicaciones como Vasconia (1963) de Federico Krutwig, sobre un legendario enfrentamiento entre vascos y españoles, una visión de un conflicto histórico que, según defendía esa versión, existe desde tiempos remotos y que únicamente concluiría con la independencia y la implantación de un estado socialista vasco. Esta acepción, ampliamente contestada por expertos como Jesús Casquete (2010, pp. 15-19), Gaizka Fernández Soldevilla (2007, p. 818) o Edurne Portella (2016, p. 19), o por recientes discursos institucionalizados, ha derivado en una censura, una tabuización, diríamos, del propio término frente a vocablos como "consenso", o "negociación”, defendidos por una economía política subvencionada por las instituciones gubernamentales vascas y que apuesta por desterrar toda terminología que incida en lo que nos enfrenta o distancia.

$\mathrm{Al}$ igual que lo que ocurriera con la literatura británica sobre terrorismo, la irrupción masiva de obras que representaban el terrorismo de ETA en nuestra literatura se dio en la década de los noventa del pasado siglo. Novelas como Gizona bere bakardadean (1993, El hombre solo) y Zeru horiek (1995, Esos cielos) de Bernardo Atxaga y la novela Hamaika pauso (1995, Los pasos incontables) de Ramon Saizarbitoria, son una buena muestra de lo que decimos, y marcaron un giro poético realista en la obra de los dos autores actuales más canónicos de nuestra literatura, Atxaga y Saizarbitoria. Se trata de novelas que presentaban la peculiaridad de focalizar mayormente los hechos narrados desde el punto de vista del victimario y su entorno, y no de la víctima, cuestión que alejaba la novela vasca de la tendencia predominante en la literatura anglosajona. Hemos solido aludir, siguiendo a Blessington (2007, p. 117), a los objetivos que pudiera haber perseguido dicho enfoque, en especial, a su objetivo didáctico de mostrar la mente del terrorista e indagar en su psicología, su situación personal... aspectos todos ellos que han incidido, a su vez, en la destabuización del terrorismo de sus elementos fetichistas y ritualizados (Zulaika y Douglass, 1996) ${ }^{3}$. Edurne Portela, por su parte, también apuntó la importancia que tiene analizar la representación del perpetrador pues, según ella, "necesitamos plantearnos y analizar críticamente qué papel juegan en nuestra imaginación esos perpetradores que, al fin y al cabo, forman parte de nuestra configuración social" (Portela, 2016, p. 126).

Sea como fuere, es obvio que las más de las 70 novelas sobre el conflicto que se han publicado desde que en $1976^{4}$, año en que Ramon Saizarbitoria publicó la novela 100 metro (Cien metros), hasta el cese de la actividad armada en octubre del 2011, la narrativa en lengua vasca sobre el tema ha desplegado todo un repertorio de características temáticas y formales que muestran claramente no solo la evolución que dicha representación ha sufrido en nuestra literatura, sino el rol cada vez más activo que el escritor vasco ha adquirido en la narración y socialización del debate sobre el mismo. Ahí está, entre las peculiaridades formales, la preeminencia que la estructura metaficcional y la reflexión sobre la escritura han tenido en muchas de ellas (Olaziregi y Ayerbe, 2016); la alusión a la represión que siguió a la Guerra Civil española como el germen de la radicalización de la política vasca y el inicio de la actividad terrorista de ETA en novelas como Soinujolearen semea, o Antzararen bidea (Olaziregi, 2015, p. 224-227); la referencia a Gernika, como lugar de memoria (Olaziregi y Otaegi, 2011); la denuncia del excesivo silencio de la sociedad vasca 
durante años, en textos como el volumen de cuentos Bizia lo (Letargo, 2003) de Jokin Muñoz o la novela Mea culpa (2011) de Uxue Apaolaza. También habría que notar la presencia cada vez más manifiesta de las víctimas secundarias en la narrativa vasca más reciente, con novelas como Zorion perfektua (La felicidad perfecta, 2006) de Anjel Lertxundi, sobre la opresión moral de la sociedad ante las víctimas y los testigos de la violencia. Es moral, también, la reflexión que Juan Kruz Igerabide realiza en novelas como Hauts bihurtu zineten (2005, Nos queda la ceniza) sobre la época de la transición. Otras novelas como Etxeko hautsa (2011, Los trapos sucios) de Anjel Lertxundi, han ahondado en el sentimiento de culpa y la difícil asunción de la responsabilidad colectiva (temática, el de la culpabilidad, también presente en novelas como Twist o Martutene que comentaremos en párrafos posteriores). Junto a todos estos aspectos, deberíamos señalar también la denuncia literaria de la política de género que ha regido la lucha armada y su representación narrativa en una sociedad heteropatriarcal como la vasca. Novelas como Koaderno gorria (1998, El cuaderno rojo), o cuentos como "Politika albisteak" ("Actualidad política"), de Eider Rodriguez reflexionan sobre el rol que el nacionalismo vasco les ha asignado mayoritariamente a las mujeres, un rol, el de apoyo moral y logístico, así como la función de madres y guardianas del hogar. Otras novelas, tales como, Boga Boga (2012) de Itxaro Borda, ahondan en el funcionamiento de ETA y su lógica militar con las mujeres.

Como vemos, desde que la narrativa vasca sobre el conflicto armado irrumpiera de forma más masiva en la última década del siglo XX en la producción literaria en euskera, las poéticas y los contenidos temáticos se han ido enriqueciendo y diversificando. Un abanico de temas y enfoques que ha ido recalando, cada vez más, no en las causas sino en las consecuencias, en los daños directos y colaterales de décadas de violencia. Algunos estudiosos, como Ibon Egaña, por ejemplo (2015, p. 4), han afirmado que más que abordar directamente la narración del conflicto armado a través de sus protagonistas (victimario-víctima), la novela vasca de las últimas décadas ha mostrado dicho conflicto en un segundo o tercer plano, como telón de fondo, diríamos, de una realidad compleja y heredada que condiciona la vida de los personajes de la trama. Es una apreciación sugerente y que, en verdad, describe muchos de los argumentos publicados recientemente. Otra cuestión es, sin duda, interpretar las consecuencias que el cese de la actividad armada han tenido en la literatura vasca. Egaña $(2015$, p. 1) afirma que dicho cese ha incrementado el número de libros que abordan el conflicto armado, aunque no sabemos si ese aumento se refiere exclusivamente a las novelas publicadas tras el cese. A priori, y a falta de estudios/cómputos rigurosos sobre el tema, no parece que el número de novelas publicadas anualmente haya sido superior al número de novelas publicadas, por ejemplo, durante los primeros 5 años del presente siglo. Lo que sí ha cambiado, sin duda, es la presencia social e institucional del debate sobre las políticas futuras a acometer para reconocer el daño causado y contribuir a la resolución del conflicto y la convivencia. Sea gracias a la institucionalización de las políticas y los estudios de la memoria (Olaziregi, 2017, pp. 254-256), sea gracias a la socialización del debate sobre el mismo, el período post-ETA ha estado marcado por la dialéctica en torno al "relato" que debemos construir, un relato inclusivo y que recoja el sufrimiento de víctimas de toda índole. Pero también sigue estando marcado por desavenencias, discusiones y polémicas en torno a cuestiones tan elementales como las estrategias y políticas educativas a seguir para, a partir del conocimiento de lo ocurrido, educar en la convivencia y en la paz ${ }^{5}$. De hecho, la propia escenificación en Cambó, País Vasco continental, de la disolución de ETA estuvo marcada por polémicas y ausencias institucionales destacadas ${ }^{6}$.

En las líneas que siguen, realizaremos un repaso a algunas de las novelas más interesantes publicadas en el período post-ETA, y nos detendremos en las novedades que presentan. Como veremos, cuestiones referentes a la herencia recibida, a los crímenes que quedaron impunes, o a las actitudes e identidades colectivas que demandan los nuevos tiempos serán los que protagonicen dicho panorama. 


\section{CONFLICTO Y TRANSMISIÓN A LAS FUTURAS GENERACIONES}

Una de las cuestiones más importantes que ha abordado la novela post-ETA es el del legado de años de terrorismo y la transmisión de la ideología que la sustenta. Ramon Saizarbitoria (1944) es, sin duda, un autor referencial en ese sentido. Ya en su novela 100 metro, apuntó una cuestión, a saber, la del nexo ideológico que algunos veían entre los gudaris (soldados) vascos que lucharon en la Guerra Civil en el bando nacionalista, y los miembros de E.T.A. . Cuestión que fue tratada con más detenimiento en su Gorde nazazu lurpean (2000, Guárdame bajo tierra), cuando en narraciones como Asaba zaharren baratza (El huerto de nuestros antepasados), el protagonista trata de "liberarse" de esa herencia nacionalista que es vivida como carga (Olaziregi, 2012, pp. 174-175).

Es en Martutene (2012), donde Saizarbitoria explicita más claramente su rechazo a la transmisión del legado de ETA. Estamos ante una novela importante, traducida al español y al inglés, cuya recepción crítica ha sido realmente reseñable, como lo atestiguan galardones como el Premio Euskadi de Literatura en 2013, el Premio de la Crítica, el Premio 111 Akademia. Además fue finalista en el Premio Nacional de Narrativa. Martutene revela, desde el inicio, una realidad y una cartografía marcada por las consecuencias de décadas de terrorismo. Los itinerarios de los personajes de la novela están impregnados por el recuerdo de víctimas como Fernando Múgica en 1996, Miguel Ángel Blanco en 1997; o por amenazados por la banda que ven su día a día aterrorizado por la posibilidad de un posible atentado. Es la novela donde la explicitación de la crítica del terrorismo en boca de personajes como Julia, la traductora, es absolutamente incontestable. Estamos ante un personaje que manifiesta alegrarse de las detenciones de los ETArras, que dice escandalizarse ante la empatía que muestra su madre por los presos de ETA y no por las víctimas de éstos, que se avergüenza de la longevidad del terrorismo y de la cobardía colectiva para no abatirlo ${ }^{8}$....una crítica sin paliativos a una realidad y un legado que Julia, además, rechaza transmitir a su hijo. En efecto, Julia, ex compañera de un etarra con quien tuvo un hijo, Zigor, se niega a mostrar a éste la carta que su padre le escribió y pidió transmitir. Frente a ese legado, ella prefiere los versos de J. Miguel Ullán para verbalizar cuál es la memoria que desea transmitir a futuras generaciones: "diles/que no hay más raza que el azar, que no hay más patria que el dolor" (Saizarbitoria, 2013, p. 295).

Es importante tener en cuenta que en Martutene son dos las mujeres/madres que intervienen en la transmisión intergeneracional del legado nacionalista: la propia Julia y su madre, la abuela de Zigor. Estamos, sobre todo en el caso de la abuela, ante un caso de memoria comunicativa plasmada en las memorias que la matriarca cuenta a Zigor. El choque dialéctico entre la abuela y la madre de Zigor hace que las reflexiones en torno a la transmisión de las memorias nacionalistas sean más complejas y enriquecedoras en esta novela. Julia matiza o cuestiona lo que la abuela le cuenta a Zigor. Por ejemplo, cuando le habla de la Guerra Civil, la abuela ensalza la figura de los gudaris, y justifica su rendición, argumentando que la guerra estaba perdida en Euskadi; también recurre a los principales símbolos o lugares de la memoria vascos (como Gernika), pero Julia cuestiona su testimonio (Saizarbitoria, 2013, p. 185), a pesar de que quiere transmitir a Zigor el orgullo que le produce la dignidad de los gudaris de la guerra, aun reconociendo que no deberían sentirse comprometidos por lealtad a sus antepasados.

Para la abuela, la represión franquista está estrechamente vinculada con la continuidad de la violencia en el País Vasco. Julia se enfrenta a ella ante Zigor, porque no quiere que le transmita ideas que a ella le parecen erróneas y perjudiciales. Y es que, a pesar de que la abuela afirma que está en contra de la violencia y que siente lástima por las víctimas, recurre al victimismo para justificar su compasión por unos jóvenes detenidos por posesión de explosivos. De nuevo, hace referencia a símbolos o lugares de la memoria de la represión sufrida por los vascos, como Gernika:

Solía refugiarse en un mutismo resignado del que volvía a salir al cabo de un rato para musitar algo parecido a "El caso es que a nosotros siempre nos toca sufrir”. Casi siempre era así, y si Julia no se lo impedía se refería a algún hecho de su larga lista de agravios, el bombardeo de Guernica, del que quisieron responsabilizar a los gudaris, el fusilamiento del tío, los veinticinco 
años que lleva preso su sobrino, las penurias y el duro trabajo de generaciones de los suyos que apenas les ha permitido salir de la miseria, la multa de diez mil pesetas a su padre por hablar euskera. Hasta que la hacía callar gritándole que a cuento de qué venía aquello y, antes de obedecerle, con mirada mártir y voz de profunda tristeza, le preguntaba: “¿Es que he dicho alguna mentira?". (Saizarbitoria, 2013, p. 128)

Con el tiempo, Julia también se ha ido oponiendo a su madre y a su hermana cuando habla con Zigor de su padre biológico, el etarra fallecido. Y es que Julia confiesa que le es cada vez más difícil hablarle de él sin desmitificar la imagen idealizada del héroe-mártir que aquellas le transmiten (Saizarbitoria, 2013, p. 129). No quiere que la vida y muerte de su padre determine a Zigor más de lo que lo hace genéticamente (Saizarbitoria, 2013, p. 130). Como vemos, las actitudes de Julia ante su madre, o ante su hijo, dan pie para cuestionar o deconstruir las identidades de género promovidas por el nacionalismo vasco y las funciones que éste atribuía a las madres. Julia no quiere ser mera transmisora, pasiva, de la batalla, guerra, que libran los hombres a favor de la patria. Y es que, como apuntaba Begoña Aretxaga, la ética del héroe redentor, propuesta como una forma de activismo,

plantea problemas en términos de identificación femenina, porque el héroe mártir es hijo y hermano. [...] La mujer militante solo puede identificarse con este modelo de luchador activo, negándose a sí misma como mujer, o como poseedora que aquello define la esencia de la masculinidad. La otra posibilidad para las mujeres es identificarse con la imagen dela madre, asumiendo el papel de mediadora. (Aretxaga, 2009, p. 23)

Julia, por tanto, se alza ante el rol de transmisora y ayudante del gudari abertzale, se niega a perpetuar una guerra que considera dañina y destructiva. Esta deconstrucción del concepto de maternidad que aborda Saizarbitoria es antagónica, por ejemplo, con el que propone Fernando Aramburu en Patria?

Atertu arte itxaron (2015, Los turistas desganados) de Katixa Agirre (1981) es, sin duda, otra de las novelas que más acertadamente ha reflexionado sobre el período post ETA. Se trata de la primera novela de la autora, tras dos libros de relatos (Sua falta zaigu, 2007; Habitat, 2009), y debemos decir que nos ha parecido tan interesante como a los lectores que le otorgaron el premio 111 Akademia. Se trata de una road novel, donde Ulia, vitoriana, mezzosoprano y doctoranda en Musicología por una tesis sobre Britten y el pacifismo, realiza un viaje en coche con su compañero Gustavo, profesor universitario en derecho internacional, por Euskadi en el verano de 2011, cuando ETA ya había declarado el alto el fuego. En realidad, son tres las historias o planos narrativos que la narración va alternando. Por un lado, está el relato mismo del viaje, con abundantes flash-backs que recalan en la relación de la pareja que comienza durante los atentados islamistas del $11 \mathrm{M}$ en Madrid, y que a medida que avanza la historia, irá revelando sus carencias y la cada vez más manifiesta crisis que viven. Por otro lado, tenemos las analepsis que muestran la genealogía familiar de Ulia, con unos padres que se conocen durante los dramáticos acontecimientos del 3 de marzo de 1976 en Vitoria, y que derivarán, en el caso del padre, a una terrible trayectoria en ETA y futura cárcel. Por último, tenemos el plano narrativo más teórico, donde la narradora reflexiona sobre la vida de Benjamin Britten, su pacifismo durante la Segunda Guerra Mundial, así como su negativa a adoptar un niño vasco exiliado en Inglaterra durante la Guerra Civil por anteponer su carrera creativa. Tres historias, en definitiva, plasmadas en una obra que tiene su receptor textual claramente delimitado, Gustavo, y que, en realidad, se convierte en la confesión de la identidad del padre de Ulia, José María Ortiz de Zarate, un ETArra que cumple condena de 980 años en la cárcel por participar en atentados terribles (y reales) como el de la calle Guzmán el Bueno de Madrid. Resaltar, además, la coincidencia de que todas las relaciones de pareja de la novela vienen marcadas/condicionadas por la violencia armada, sea del índole que sea. Estamos ante una realidad donde las memorias de los diferentes conflictos armados no compiten entre ellas, sino que trabajan productivamente, como afirma Michael Rothberg (2011, p. 523), para dibujar un mapa no tan local donde la violencia está también presente.

"Me propones esperar hasta que escampe. Me río de ti, pobre diablo" (Aguirre, 2015, p. 40). Es la irónica voz de la narradora, Ulia, dirigida a su compañero y que bien pudiera ser uno de los mensajes de la novela: esperar a que escampe, a que lleguen mejores momentos para afrontar un problema no es, en verdad, la solución. Y el problema con mayúsculas que tiene Ulia, es, sin duda, la revelación que le hace su madre sobre 
la identidad de ese "padre ausente" (Aguirre, 2015, p. 134) que ha marcado su vida: un miembro de ETA con un sanguinario listado de asesinatos a su espalda y que durante el viaje que la pareja está realizando a Euskadi se encuentra gravemente enfermo y en huelga de hambre por un aumento de la condena. "Las culpas del padre. Las cargas de la hija. Cargaré con la culpa de mi padre” (Aguirre, 2015, p. 176), he ahí la reflexión que realiza la novela sobre el legado que recibirá parte de la sociedad vasca. Un pasado desconocido para Ulia, pero que le asedia durante el viaje por las continuas imágenes y noticias que tanto en los medios como en los lugares que frecuentan (bares, etc.) le recuerdan a su padre.

Y ya que hemos aludido a los medios de comunicación, es más que notable la reflexión que la novela plantea a propósito del protagonismo que tienen y han tenido éstos en la cobertura del denominado "problema vasco". En realidad, la importancia que los teóricos y estudiosos del terrorismo atribuyen a los medios de comunicación ha sido, desde siempre, notable. Alex Houen (2002, p. 11), sin ir más lejos, habla de relación simbiótica entre ambos. En la novela que nos ocupa, la avalancha de noticias e imágenes tras el atentado del $11 \mathrm{M}$ en Madrid ahonda en el estigma que como vasca tener ante personas ajenas al mundo vasco, el estima de ser un etarra/proetarra. Ulia lo ejemplifica perfectamente en el temor que tiene por el futuro de su relación con Gustavo: "Si finalmente no ha sido ETA, puede que me llame, pueda que lo vuelva a ver" (Aguirre, 2015, p. 61). Hablamos de unos medios de comunicación que son criticados por Ulia por su gusto por la explicitación de cadáveres destrozados tras los aludidos atentados islamistas (Aguirre, 2015, p. 54), por el amarillismo y uso de términos como "reino de terror" (Aguirre, 2015, p. 86), una prensa que, además, se dice que ha evolucionado tras el anuncio del alto el fuego a una actitud excesivamente "favorable" a los vascos como "reacción a la sobreexposición negativa que habéis tenido en los medios" (Aguirre, 2015, p. 95). Gustavo llega a afirmar, incluso, que "si no fuera por ETA, nadie habría oído hablar de los entrañables Basque people" (Aguirre, 2015, p. 95). Una realidad, la de la cobertura del conflicto vasco por parte de los medios de comunicación (cf. Ramírez de la Piscina et al., 2016), que la escritora Katixa Agirre conoce bien por su condición de Doctora en Comunicación Audiovisual y profesora de la Facultad de Ciencias de la Información de la Universidad del País Vasco. Una realidad mediática, en definitiva que horroriza a Ulia por el temor al interés morboso que puede generar la identidad de su padre entre los periodistas como Sara, quien recorre "escenarios del terror [sic]" (Aguirre, 2015, p. 170) por Euskadi.

En resumen, Los turistas desganados busca reflexionar sobre la responsabilidad colectiva heredada por décadas de terrorismo, y por la injusticia de cargar con la culpa de las acciones cometidas por otros. Y es que, tal y como argumentó Hannah Arendt, "[e]xiste una responsabilidad por las cosas que uno no ha hecho, a uno le pueden pedir cuentas por ello. Pero no existe algo así como el sentirse culpable por cosas que han ocurrido sin que uno participase activamente en ellas" (Arendt, 2007, p. 151) ${ }^{10}$.

\section{UNA NOVELA SOBRE LAS VÍCTIMAS DE LA GUERRA SUCIA}

Otra novela absolutamente destacable de los últimos años es, sin duda, Twist (2011), de Harkaitz Cano (1975), uno de los autores referenciales del panorama literario vasco actual (Olaziregi, 2012, pp. 185-187; 2016). La trayectoria literaria de Cano incluye todos los géneros literarios, así como híbridos que gustan de experimentar los límites expresivos de las diferentes creaciones artísticas. Podríamos decir que la publicación de Twist en 2011, no dejó indiferente ni a lectores ni a crítica. Galardonada con el Premio Euskadi de Literatura en 2012, el Premio de la Crítica y el Beterriko Liburua, sus traducciones al español (Seix Barral, 2013), búlgaro, serbio o inglés (Archipielago Books, 2016), son un ejemplo de la excelente acogida que todavía hoy sigue teniendo la obra. Su peculiaridad y originalidad viene marcada por cuestiones temáticas, por un lado, y por formales, por otro, ya que la historia que se narra se inspira en un caso real de terrorismo de estado, y además, lo hace utilizando una poética fantástica, realmente poco frecuente en la narrativa contemporánea sobre el conflicto vasco. 
La novela tiene como punto de partida la desaparición y el asesinato de dos militantes de un grupo armado, Soto y Zeberio. Un tercer militante y amigo de ambos, Diegu Lazkano, se siente responsable de su muerte porque fue él quien les delató. Durante más de veinte años la sombra de sus amigos acechará a este personaje, incluso tratará, en algunos aspectos, de suplantar sus vidas. Pero será el sentimiento de culpa que le embarga constantemente, la investigación en torno a los hechos acaecidos, su imposibilidad para narrar lo inconfesable, lo que condicionará el desarrollo de los acontecimientos.

Es fácil vislumbrar los equivalentes reales de las dos víctimas desaparecidas. Se trata de José Antonio Lasa y José Ignacio Zabala, miembros de ETA, que fueron detenidos, torturados y asesinados en 1983 por los GAL, grupos parapoliciales españoles que practicaron el terrorismo de estado. Sus cuerpos fueron enterrados en cal viva, encontrados en 1985 e identificados en 1995. La presencia espectral de esos muertos condicionará el capítulo introductorio de la novela, emulando páginas conocidas de la literatura mundial, tales como, $A s$ I lay Dying, de Faulkner. Esa presencia espectral, ese cuerpo torturado que despierta y aparece de repente, simboliza la resistencia ante el crimen que ha quedado impune. Como dice Jacques Derrida en Spectres of Marx:

Hay que hablar del fantasma, incluso al fantasma y con él, desde el momento en que ninguna ética, ninguna política, revolucionaria o no, parece posible, ni pensable, ni justa, sino reconoce como su principio el respeto por esos otros que no son ya o por esos otros que no está todavía ahí, presentemente vivos (Derrida, 1995, p. 13).

El fantasma, por lo tanto, nos revela un macabro crimen ocurrido en el pasado. Además, las referencias intertextuales a los desaparecidos del Cono Sur durante las dictaduras de las décadas de 1970 y 1980, convierte la novela de Cano en un buen exponente de la memoria multidireccional y transnacional que hace alusión a esos seres que, como reza la ley 24.321 argentina, no están ni vivos ni muertos: “¿No es hermoso estar vivo? Pero tú no estás vivo exactamente, estás muerto y despierto. No es lo mismo” (Cano, 2011, p. 33).

Destacan, asimismo, las variadas reflexiones metaficcionales, reflexiones que buscan indagar en binomios como amistad/traición, originalidad y plagio, y donde, ante todo se trata de cuestionar la capacidad que tiene la ficción para narrar el horror. “¿Puede sublimarse con el arte la tortura? ¿Puede superarse el terror a través del arte?” (Cano, 2011, p. 375), he ahí dos de las preguntas más importantes que nos plantea el narrador de la novela.

Solo al final de Twist vislumbraremos una de las respuestas posibles que aporta el texto ante el estremecimiento que nos causa una realidad política terrorífica: la literatura no es suficiente, pero escribir puede curar y redimirnos (Cano, 2011, p. 493).

\section{El CONFLICTO DESDE EL HOGAR: LA PEQUEÑA gUERRA (2014) DE LANDER GARRo}

Una de las peculiaridades a reseñar de la novela de las dos últimas décadas es la aparición de narraciones de corte más o menos autobiográfico de protagonistas del entorno de ETA. Narraciones tan variadas temáticaformalmente como Mentxakaren aitorpena (2005, La confesión de Mentxaka) de Jose Ramon Goikoetxea, Errotarria (2006, El Molino) de Jokin Urain, Ospitalekoak (2010, Desde el hospital) y Atzerri (2012, Exilio) de Mikel Antza, o Gaur zortzi (2012, Dentro de 8 dias), de Carmen Gisasola, son un ejemplo de lo que decimos. También tiene un trasfondo autobiográfico Gerra txikia (2014, La pequeña guerra) del escritor Lander Garro (1975), autor, entre otros, de las novelas Orain galdera berriak ditut (2004, Ahora tengo preguntas nuevas) y Kontrarioa (2010, El contrario).

Guerra txikia narra la historia de Xabi Ugarte y su familia durante los años en que deben exiliarse en Hendaia. Es la mirada inocente de Xabi la que guía la narración, una mirada y un tono convincente que cobran ritmo en una novela que pudiéramos calificar de formación. Y es que Gerra txikia es, además, un relato del despertar de Xabi ante la realidad política vasca durante unos duros años 80 marcados por la violencia de ETA y de los GAL, las drogas (“Camellos fuera”, Garro, 2014, p. 57), todo ello ampliamente representado 
en la novela. El viaje a Hendaia que Xabi, junto a sus hermanos Gotzon y Nagore y su madre, realiza en 1983 en tren desde Rentería, se convierte en el primero de los que tendrán que hacer durante varios fines de semana hasta instalarse definitivamente en Iparralde (Euskal Herria continental). Tras 65 días sin regresar a casa "a causa de la inundaciones", su padre les confirma que no puede volver a casa; "no me dejan" (Garro, 2014, p. 13), dice. Y ahí comienza, sin duda el despertar de Xabi que pasa por palabras y realidades como "refugiado" (Garro, 2014, p. 30), "Libertad de Euskadi" (Garro, 2014, p. 32), un lenguaje y una realidad al principio desconocida para un niño que no duda en afirmar que "¿Qué le importaban a él la amnistía o la libertad de Euskadi, si no podía estar con su madre? (Garro, 2014, p. 32). Una “vida nómada” (Garro, 2014, p. 79), en definitiva, que marcará la dinámica familiar de un niño "enclenque, de espalda estrecha y brazos que parecían palos" (Garro, 2014, p. 79) y que, además, sufre de enuresis ("Xabi sesele pipi en la cam") en medio de una precariedad y caos familiar notable.

Entre consignas a favor de la amnistía (Garro, 2014, p. 93) y de los refugiados políticos vascos (Garro, 2014, p. 128), la familia peregrinará de una casa a otra, y vivirá en sus carnes la escasez de medios y el miedo a un posible atentado. La Patria lo es todo para un padre que tiene dificultades para mostrar sus afectos (Garro, 2014, p. 133), no cede ante ningún deseo de los hijos, y es incluso calificado de "ogro" "sanguijuela" o "cabrón" (Garro, 2014, p. 88). Aterrorizado con la idea de que, al igual que sus colegas Emilio o Txomin, sea el siguiente objetivo de los GAL, el padre arrastra a su familia hacia un destino, el exilio en Hendaia, población que a los ojos de los hijos se antoja cuasi fantasmal (Garro, 2014, p. 27). En él habitan la comunidad de vascos que los acogerán y que, en realidad, viven como un guetto, apartada de la Hendaia "real" (Garro, 2014, p. 154). En él vivirá Xabi sus primeros amores, sus problemas escolares..., así como la sensación claustrofóbica por la habitación-trastero en que deben dormir (Garro, 2014, p. 103). Será Gotzon, el hermano mayor, quien mejor ejemplifique la oposición ante la autoridad paterna. Próximo a la estética y el pensamiento punk, admirador de las canciones de Kortatu (Garro, 2014, p. 144), Leño, GBH, Sex Pistols, La Polla Records... (Garro, 2014, p. 184), cuasi incomprensibles para el pequeño Xabi (Garro, 2014, p. 143), Gotzon muestra un comportamiento y un lenguaje duro, plagado de términos militares y que subraya al hermano pequeño, Xabi, que, en realidad, están en medio de una guerra (Garro, 2014, p. 106).

...lo que Xabi hubiera querido de verdad era volver a Rentería y recuperar su antigua vida. O no exactamente su vida, con sus fracasos, sino más bien la ligereza de aquella vida pasada. La seguridad de que las cosas eran y seguirían siendo para siempre. Eso era lo que hubiera querido, una vida sin miedos y gente desconocida que hacía preguntas que exigían respuestas exageradas y falsas. Pero estaba claro que tendría que conformarse con una granadina. (Garro, 2014, p. 63)

Es muy interesante la reflexión que la novela plantea en torno al conflicto armado, las Guerras (con mayúscula) y la guerra pequeña (sic), es decir, la del día a día, la doméstica. La constante oposición entre los lugares de la memoria que abundan en la zona vasco-francesa, tales como, los bunkers que construyeron los nazis durante la Segunda Guerra mundial (Garro, 2014, p. 106), recuerdan a Xabi que está ante una geografía marcada por unas memorias de guerra trágicas que vuelven "pequeñas" las limitaciones que viven en casa:

A Xabi le pareció increíble que los nazis hubieran estado en el mismo sitio en el que estaba él ahora, y le pareció que todo el asunto de la casa y la sala se hacía pequeño e insignificante. (Garro, 2014, p. 106)

Se trata, sin duda, de un ejemplo de memoria multidireccional, donde las memorias de otros conflictos y guerras confluyen y confrontan los conflictos actuales. Éste es el caso, también, de la interpretación que la madre les propone ante el terror que viven tras el asesinato del refugiado Txomin a manos de los GAL. La madre no duda en compararlo con el terror que el abuelo Paco vivió en la Guerra Civil:

Luego empezó a hablar del aitona Paco, y contó que se pasó toda la vida con miedo, sin poder ponerle palabras a lo que había vivido en la guerra y que murió del mismo modo, mudo y sin emitir una sola queja.

-Una guerra de tres años y cuarenta años de silencio -dijo-. Ese es el poder del terror. (Garro, 2014, p. 199) 
Una novela, en definitiva, que nos ofrece un punto de vista, el del hijo del miembro de ETA, absolutamente novedoso dentro del panorama narrativo vasco y lo hace de un modo convincente.

\section{UNA NUEVA IDENTIDAD COLECTIVA PARA LOS TIEMPOS DE PAZ: JENISJOPLIN (2017), DE UXUE Alberdi}

En 2017 hizo su aparición la novela Jenisjoplin (2017) de Uxue Alberdi (1984), autora que pertenece, a la ultimísima generación de escritoras vascas. Se trata de la segunda novela de la autora, tras la exitosa $A u l k i$ jokoa (2009, El juego de las sillas), una narración ambientada en la Guerra Civil y que narra la sexualización de la represión franquista durante la contienda en el País Vasco. Por su parte, Jenisjoplin ha obtenido galardones como el premio 111 Akademia y será pronto traducida al inglés y publicada por el CBS.

Jenisjoplin, plantea una historia original y rompedora, por cuanto rememora, en boca de su protagonista Nagore Vargas, apodada Jenisjoplin, la convulsa realidad socio-histórica de las cuatro últimas décadas en el País Vasco, décadas que, en especial la de los años 80, estuvieron condicionadas por la violencia terrorista, el paro, las luchas obreras, las drogas y el sida. Hablamos, como se menciona en la novela, de una generación marcada, entre otros, por el Punk y por su lema, no future, y que en la primera década de los XXI se ve en la necesidad de evolucionar de una identidad nacional resistente, a una identidad vulnerable que trate de superar el trauma de culpabilidad que la ha acechado por décadas de violencia. Diríamos, además, que más que un comportamiento coyuntural, la violencia, la rabia, la provocación, el riesgo, constituyen el eje que condiciona todos los afectos de Nagore, entendidos éstos en el sentido que les atribuyen Sara Ahmed y otros, es decir, como lo que une, sostiene o preserva la conexión entre ideas, valores y objetos (2010, p. 29); dicho de otra manera, no como estados psicológicos sino prácticas sociales y culturales (Ahmed, 2004, p. 9). La joven adolescente Nagore no duda en pelearse con un cliente en uno de los bares que la familia regenta a los largo de los años cuando éste le compara con la "retrasada de su madre" (Alberdi, 2017, p. 128), tiene tendencia a la autopunición desde pequeña (Alberdi, 2017, p. 74), y goza de subidones de adrenalina tras una reyerta (Alberdi, 2017, p. 143). La violencia forma parte de su día a día, una violencia que tiene parte de su origen en su relación con el padre, una relación edípica donde complacer al pater familias significa, ante todo, arriesgar, luchar, pelear. Nagore afirma sentirse como una bomba cuyo detonador activa su padre (Alberdi, 2017, p. 158). Asustarse, significa, en la lógica de padre e hija, ser débil (Alberdi, 2017, p. 147), someterse (Alberdi, 2017, p. 148).

Apropiándonos del conocido título de Laurent Berlant (2011), diríamos que el corazón de la nación vasca, ha estado durante décadas tristemente sustentado en el odio y el dolor colectivo, el terrible dolor causado por décadas de conflicto armado. Es por ello que el anuncio del alto el fuego por parte de ETA el 5 de septiembre de 2010 es vivido por la protagonista con una reacción bastante escéptica:

Los ritmos marcados por ETA, la densidad del aire, los ciclos y las interrupciones: las sístoles y diástoles de las emociones colectivas guiadas por ETA se habían callado. El cuerpo estaba aún caliente. Alrededor, sus viudos y viudas, sus enemistades y amistades, sus sucesores, plañideros y buitres. La alegría no era limpia. La tristeza estaba sucia.

Lo que resulta llamativo de la novela que nos ocupa, no es la utilización del sida para metaforizar y denunciar, como alude Susan Sontag en su conocido libro (1996, p. 145), toda una política de la voluntad de intolerancia, de paranoia, de miedo a la debilidad política, sino para simbolizar, a través de este cuerpo enfermo una identidad colectiva, la vasca, que ha pasado de la épica del héroe y la violencia, de una identidad donde la lucha (armada o no), la fuerza y la ira eran las marcas más características de identidad nacional (1996, p. 250), a una identidad débil, vulnerable, que necesita reinventarse si quiere tener futuro. Como afirma Nagore en la novela:

Uno de los ejes que dividía nuestro mundo acababa de desaparecer. Atrás quedaban la tensión y la seguridad de tener que posicionarse o ser posicionada inevitablemente. El tragar saliva. La adrenalina de la enemistad. La cuna de la colectividad. La 
conciencia del sufrimiento era amplia, larga y poliédrica. El tiempo para la reconstrucción de las identidades comenzó a las 19 de la tarde. La imagen desvirtuada que teníamos del pueblo, de nosotras mismas e incluso del resto empezaría a concretarse, sería un proceso que se daría de forma individual, de dos en dos, de tres en tres o en grandes grupos. En busca de una nueva verdad. En busca de mentiras actualizadas que se adaptaran a la razón y la moral de los nuevos tiempos. Tendríamos que regular el vocabulario, la mirada y la actitud.

La novela muestra, a través de la relación que Nagore tiene con Luka, que aún sabiéndose amenazados por la enfermedad, la felicidad es posible. Y lo es, gracias a esos objetos, los objetos felices los llama Ahmed, a los que nos sentimos atraídos por la promesa que encierran. La familia, será, como afirmó la feminista británica uno de ellos, y será precisamente la unión familiar que Nagore experimenta al final de la novela la que marcará el inicio del tratamiento con los antiretrovirales, y su decisión de rodearse de objetos que mantienen esa promesa de felicidad.

De ahí el final esperanzador y que presenta la novela. La pareja mira al futuro en un entorno donde la mirada ya no recala en escenas de violencia y exclusión, sino en muestras de afecto e itinerarios que ya no son, solamente, lugares de memoria de un pasado político convulso.

\section{Conclusiones}

En las líneas precedentes, hemos tratado de ofrecer una lectura de las novedades que, en nuestra opinión, ofrece la novela en lengua vasca tras el alto el fuego de ETA. Podríamos afirmar que aunque el alto el fuego no ha incidido, hasta el momento, en un destacado aumento de la producción novelesca sobre el tema, sí que pudiera haber incidido en el tratamiento literario de los debates y polémicas que están marcando el nuevo período. La presencia más manifiesta de las víctimas de la violencia terrorista de diversa índole, la reflexión en torno a las actitudes e identidades nacionales y políticas que deben impulsarse, la puesta por el reconocimiento del daño causado y por la convivencia, los daños colaterales (sociales, familiares) del conflicto, la preocupación por la herencia de décadas de violencia....son, sin duda, algunos de los temas que hemos vislumbrado en la ultimísima producción novelesca, una producción que hace suya diversidad de poéticas y recursos formales. No sabemos si la mejor literatura sobre el nuevo período está por llegar, pero sí podemos afirmar que la narrativa vasca sigue aportando su grano de arena para una memoria cultural diversa e inclusiva para las futuras generaciones.

\section{ReFERENCIAS}

Apaolaza, Uxue (2011). Mea Culpa. Donostia: Elkar.

Ahmed, Sara (2004). The Culture Politics of Emotion. Londres: Routledge.

Arendt, Hannah (2007). Responsabilidad y juicio. Barcelona: Paidós.

Arrieta, Leyre (2015). ETA y la espiral de la violencia. Estrategias y víctimas. En Pilar Rodríguez (Ed.), Imágenes de la memoria. Victimas del dolor y la violencia terrorista (pp. 21-52). Madrid: Nueva Biblioteca.

Atxaga, Bernardo (1993). Gizona bere bakardadean. Iruñea: Pamiela. [Traducción al español: (1994). El hombre solo. Trad. de Arantzazu Sabán y Bernardo Atxaga. Barcelona: Ediciones B.]

Atxaga, Bernardo (1995).Zeru horiek. Donostia: Erein. [Traducción al español: (1995). Esos cielos. Trad. de Arantzazu Sabán y Bernardo Atxaga. Barcelona: Ediciones B.]

Atxaga, Bernardo (2003). Soinujolearen semea. Iruñea: Pamiela. [Traducción al español: (2004). El hijo del acordeonista. Trad. de Asun Garikano y Bernardo Atxaga. Madrid: Alfaguara.]

Berlant, Laurent (2011). El corazón de una nación. Mexico: FCE.

Bister, Daniela (2015). La construcción literaria de la víctima. Guerra Civil y Franquismo en la novela castellana, catalana y vasca. Frankfurt: Peter Lang. 
Blessington, Francis (2007). Politics in the terrorist novel. Sewanee Review, 116(1), 116-124.

Borda, Itxaro (2012). Boga boga. Zarautz: Susa.

Casquete, Jesús (2010). Abertzale sí, ¿pero quién dijo de izquierdas? El viejo topo, 68, 15-19.

Cano, Harkaitz (2011). Twist. Zarautz: Susa. [Traducción al español: (2013). Twist. Trad. de Gerardo Markuleta. Barcelona: Seix Barral.]

Fernández Soldevilla, Gaizka (2007). El nacionalismo vasco radical ante la transición española. Historia contemporánea, 35, 817-844.

González Katarain, María Dolores (2009). Yoyes, desde su ventana. Irun: Alberdania.

Houen, Felix (2002). Terrorism and Modern Literature, from Joseph Conrad to Ciaran Carson. Oxford: Oxford University Press.

Igerabide, Juan Kruz (2005). Hauts bihurtu zineten. Irun: Alberdania. [Traducción al español: (2008). Nos queda la ceniza. Irun: Alberdania.]

Lertxundi, Anjel (1983). Hamaseigarrenean aidanez. Donostia: Erein.

Lertxundi, Anjel (2002). Zorion perfektua. Irun: Alberdania. [Traducción al español: (2006). La felicidad perfecta. Trad. de Jorge Giménez. Irun: Alberdania.]

Lertxundi, Anjel (2011). Etxeko hautsa. Irun: Alberdania. [Traducción al español: (2011). Los trapos sucios. Trad. de Jorge Giménez. Irun: Alberdania.]

Muñoz, Jokin (2003). Bizia lo. Irun: Alberdania. Traducción al español: (2005). Letargo. Trad. de Jorge Giménez. Irun: Alberdania.]

Muñoz, Jokin (2007). Antzararen bidea. Irun: Alberdania. Traducción al español: (2009). El camino de la Oca. Trad. de Jorge Giménez. Irun: Alberdania.]

Olaziregi, Mari Jose (2012). Worlds of Fiction: An Introduction to Basque Narrative. En Mari Jose Olaziregui, Basque Literary History (pp. 137-200). Reno: Center for Basque Studies, University of Nevada.

Olaziregi, Mari Jose (2016). Hain hilik, hain bizirik. Harkatiz Canoren Twist edo belarrak ezabatu ez zuena. En Izaro Arroita y Lourdes Otaegi (Eds.), Oroimenaren lekuak eta lekukoak (pp. 171-184). Bilbao: Servicio Editorial Universidad del País Vasco.

Olaziregi, Mari Jose (2017). Literature and Political Conflict: the Basque Case. En Xabier Irujo y Mari Jose Olaziregi (Eds.), The International Legacy of Jose Antonio Agirre's Government (pp. 251-278). Reno: Center for Basque Studies-University of Nevada.

Olaziregui, Mari Jose (2018). A vueltas con la madre patria. Passés Futurs, 3. Recuperado de https://www.politika.io /fr/notice/a-vueltas-con-madre-patria. Accedido el 1/11/2018

Olaziregi, Mari Jose, y Ayerbe, Mikel (2016). El conflicto de la escritura y la rescritura de la identidad: análisis de la narrativa de escritoras vascas que abordan el conflicto vasco. En Katarzyna Moszczynska-Dúrst, Karolina Kumor, Ana Garrido y Aranzázu Calderón (Eds.). Identidad, género y nuevas subjetividades en las literaturas hispánicas (pp. 45-66). Varsovia: Universidad de Varsovia-Instituto de Estudios Ibéricos.

Portela, Edurne (2016). El eco de los disparos. Barcelona: Galaxia Gutenberg.

Ramírez de la Piscina Martínez, Txema, Murua Uria, Imanol y Idoiaga Arrospide, Patxo (2016). Prensa y conflicto vasco (1975-2016): Recopilatorio de actitudes y vicisitudes. Revista Latina de Comunicación Social, 71, 1007-1035. Recuperado de http://www.revistalatinacs.org/071/paper/1132/52es.html. doi:10.4185/ RLCS-2016-1132

Rodríguez, Eider (2004). Politika albisteak. En Eider Rodríguez. Eta handik gutxira gaur. Zarautz: Susa. [Traducción al español: (2007). Actualidad política. En Eider Rodríguez. Y poco después ahora. Donostia: Ttarttalo.]

Rodríguez, Pilar (Ed.) (2015). Imágenes de la memoria. Victimas del dolor y la violencia terrorist. Madrid: Biblioteca Nueva.

Rothberg, Michael (2011). From Gaza to Warsaw: Mapping Multidirectional Memory. Criticism, 53(4), 523-548.

Saizarbitoria, Ramon (1976). Ehun metro. Donostia: Kriselu. [Traducción al español: (2017). 100 metros. Trad. de Piñar Muñoa. Donostia: Erein.] 
Saizarbitoria, Ramon (1995). Hamaika pauso. Donostia: Erein. [Traducción al español: (1996). Los pasos incontables. Trad. de Jon Juaristi. Madrid: Espasa Calpe.]

Saizarbitoria, Ramon (2000). Gorde nazazu lurpean. Donostia: Erein. [Traducción al español: (2002). Guárdame bajo tierra. Trad. de Fudanción Eguia Careaga. Madrid: Alfaguara.]

Saizarbitoria, Ramon (2012). Martutene. Donostia: Erein. [Traducción al español: (2013). Martutene. Trad. de Madalen Saizarbitoria. Donostia: Erein.]

Sontag, Susan (1996). La enfermedad y sus metáforas, y el Sida y sus metáforas. Madrid: Santillana.

Urretabizkaia, Arantxa (1998). Koaderno gorria. Donostia: Erein. [Traducción al español: (2002). El cuaderno rojo. Trad. de Iñaki Iñurrieta. Donostia: Ttarttalo.]

Zaldua, Iban (2016). Conflicto (vasco) y literatura (en euskera) 1973-2013. Bulletin of Hispanic Studies, 93, 1141-1156.

Zulaika, Joseba, y Douglass, William (1996). Terror and Taboo: The Follies, Fables, and Faces of Terrorism. New York: Routledge.

\section{Notas}

1 Artículo publicado dentro de los proyectos IT 1047-16 (Gobierno Vasco), US 10/17 (Universidad del País Vasco) y FFI2017-84342-P (Mineco).

2 Cf. https://eibar.org/blogak/volga/zutabeak-etaren-osteko-euskal-literaturaren-bilakabide-baterako (accedido el 26-10-2018).

3 Como mencionan M. Frank y Eva Gruber (2012, p. 12), entre la abundante bibliografía sobre terrorismo, la publicación de los antropólogos Joseba Zulaika y William Douglass, Terror and Taboo: The Follies, Fables and Faces of Terrorism (1996), ha resultado realmente interesante para los estudios literarios, por cuanto entienden el terrorismo como discurso, o por decirlo en sus palabras: "In the beginning was the word... terrorism. The various types of fictionalization representations by the media, political manipulation, academic definitions, the imaginary archetype informing the thriller- find their genesis and nourishment in the play with meaning and confusion of contexts inherent in the word 'terrorism"' (1996, p. 16).

4 Unas 26 novelas en el siglo XX, y el resto en el siglo XXI.

5 En el momento de la redacción de este artículo, una unidad didáctica, "Herenegun!", sobre la historia reciente de Euskadi e impulsada por Gogora: Instituto de la Memoria, la Convivencia y los Derechos Humanos del Gobierno Vasco ha generado una fuerte polémica parlamentaria, polémica que incluso amenaza con llegar al congreso de los diputados en Madrid. Cf. https://www.eitb.eus/es/noticias/politica/detalle/5928717/programa-herenegun-criticas-pse-pp-covite-a vt-18-octubre-2018/ (accedido el 2/11/2018).

6 Mikel Ormazabal / Luis R. Azpiolea: "ETA anuncia su disolución", El Pais, 3/5/2018 (cf. https://elpais.com/politica/ 2018/05/03/actualidad/1525336524_523980.html. Accedido el 2/11/2018)

7 El protagonista recuerda, justo antes de morir, la predicción que hizo sobre él su padre: "éste será gudari" (Saizarbitoria, 2016, p. 81).

8 que el protagonista acude al velatorio de un guardia-civil asesinado por ETA. También es interesante, sin duda, por la reflexión que realiza en torno al duelo y la convivencia la tercera novela del escritor Juanjo Olasagarre (1963), Poz aldrebesa (2017, Alegría confusa). Aunque el argumento central de la novela gire en torno a la relación entre la pareja gay Axi y Joseba, y el cuidado/duelo al que tiene que enfrentarse uno de ellos ante la enfermedad del otro, la novela incorpora referencias a documentales reales como Aulki hutsak (Sillas vacias), sobre el duelo y la muerte, así como a iniciativas políticas como la denominada Eraikiz (Construyendo), que quiere impulsar la reconciliación y reconocimiento del dolor y duelo causado por décadas de violencia política y que tuvo una de sus escenificaciones más llamativas en el ayuntamiento de Rentería, también mencionado en la novela.

9 Para una comparación entre los roles de género en Martutene y Patria, v. Olaziregui (2018).

10 Además de lo comentado, podríamos ampliar el comentario y establecer nexos intertextuales con otras novelas vascas sobre el conflicto o la Guerra Civil. Tal es el caso de la aludida Hamaika pauso (1995) de Ramón Saizarbitoria, que también incluye un personaje, Ortiz de Zarate, personaje que, además, vuelve a cobrar vida en narraciones como Satorrak baino lurperago (2000, Bajo tierra, como los topos), de Pedro Alberdi. Por su parte, la novela Mussche (2011, Lo que mueve el mundo) de Kirmen Uribe, narra la historia de la niña vasca exiliada, Karmentxu Cundín, que, al contrario de lo que ocurre en la novela de Agirre, sí encuentra una familia de acogida en Bélgica. Por último, subrayar que Los turistas 
desganados incorpora, al igual que lo hacía la novela Bilbao, New York, Bilbao, textos de diferente formato y expresión, tales como recetas culinarias, extractos de periódicos, señales de tráfico, etc.

\section{BY-NC-SA}

